\section{Vol No: 4, Issue: 2}

Received Date: May 09, 2019

Published Date: Jun 13, 2019

\section{González Rodríguez Mónica}

Palacios Juárez Julio

Sashida Mendez Hirosi

Hanson Viana Erik

Franco González Samantha

Hospital General de México, Mexico.

Corresponding Author:

\section{González Rodríguez Mónica*}

Hospital General de México “Dr. Eduardo Liceaga” Doctor Balmis No. 148, Col. Doctores. Delegación Cuauhtémoc, C.P. 06726, Ciudad de México, Mexico.

\title{
Thoracic Reconstruction. Number of Cases
}

\section{ABSTRACT:}

The reconstruction of the thoracic wall continues to be a great challenge for the plastic surgeon, since there is no precise algorithm to carry it out; due to the complexity of the thorax, there are multiple alternatives to perform the reconstruction, this involves the restoration of pulmonary physiology, stabilization of the thorax and adequate coverage of soft tissues. Five reconstructions were carried out over 3 years (January 2015-March 2018). These were carried out with pediculated muscle flaps, the patients were followed for a year, in this time interval the death of a patient was reported at 3 months, due to oncological recurrence, however, no associated complications to the procedure were reported. The reconstruction in patients with thoracic pathologies, are of great complexity, adequate coverage should be provided, also stability to the thorax and an aesthetic result as satisfactory as possible, the use of pedicled flaps provides a vascularized tissue, to return the integrity of the thorax.

Keywords: Reconstruction Thoracic; Pedicled Flaps; Thoracic Pathologies; Coverage Vascularized Tissue.

\section{INTRODUCTION}

There are pathologies that are associated with the reconstruction of the thoracic wall, these are: after a resection of primary or recurrent tumor, radiation injuries, trauma, infection or congenital diseases. The reconstruction of the thoracic wall continues to be a great challenge for the plastic surgeon, since there is no precise algorithm to carry it out; due to the complexity of the thorax, there are multiple alternatives to perform the reconstruction, this involves the restoration of pulmonary physiology, stabilization of the thorax and adequate coverage of soft tissues [1].

The decision of which type of reconstruction is suitable to perform, as for the patient, depends on multiple factors: defect size, location, depth and etiology [2]. The main objectives are: to achieve the stability of the thoracic wall and to have a reliable and well vascularized coverage of the soft tissues [3]. The secondary objectives are to avoid: a pulmonary hernia, the paradoxical movement, the contraction of the wound of the affected hemithorax, the impaction of the scapula, as well as protecting the underlying mediastinal organs and finally returning the thorax in an aesthetically acceptable way.

\section{MATERIAL AND METHODS}

We present a series of 5 patients with large thoracic defects, of different pathologies, along 3 years (January 2015-March 2018). In them we summarize different types of reconstructions, remember that 
this type of patients have a general compromised state, from an infectious process to a tumor, so it exacerbates the reconstructive difficulty and the surgical procedure. The general condition, laboratory and imaging studies were evaluated preoperatively and the absence of metastasis in the oncological patient.

The tumor resection of the affected area and the reconstruction was in the same surgical act, while, in cases associated with infection or trauma, the reconstruction was performed in a second time, once the septic process was resolved.

Patients were extubated without complications or pneumothorax. There was one decease secondary to tumor recurrence.

\section{RESULTS}

\section{Case 1}

A 30-year-old man who suffers chest trauma, undergoing with tension pneumothorax, presenting rib fractures of the fourth and fifth ribs, with a bloody area with bone exposure and osteosynthesis material in the left hemithorax, leaving a right lateral area of $12 \mathrm{~cm}$ transverse, $2 \mathrm{~cm}$ deep and $4 \mathrm{~cm}$ long, without achieving adequate coverage, finding the area tense and with risk of exposure of the osteosynthesis material by primary closure, with a BMI less than $20 \mathrm{~kg} / \mathrm{m} 2$, scarce fatty tissue in the thorax and abdomen, so a pediculated muscle flap of rectus abdominis is proposed for the reconstruction, on the skin we proceed to do a first intention closure, in the abdomen mesh and primary closure is used, the post-surgical followup without complications, without bulging or deformities in the donor's place, and with an adequate aesthetic result, no complications were reported at one year of follow-up.

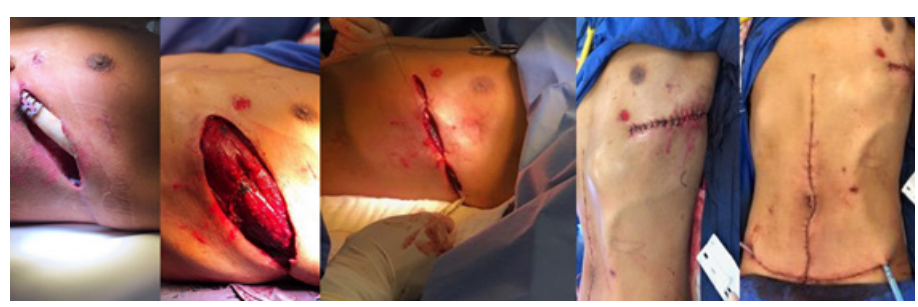

\section{Case 2}

A 56-year-old patient referred to thoracic surgery who underwent with community-acquired pneumonia, basal empyema in the right hemithorax treated with lavage and decortication, submitted to negative pressure therapy for 21 days, presenting 2 bronchopleural fistulas of $3 \mathrm{~mm}$, reconstruction was performed with muscle serratus anterior flap and primary skin closure. In the post-surgical follow-up there were no complications and an aesthetically satisfactory result was obtained, one year after the reconstruction the patient remains asymptomatic.

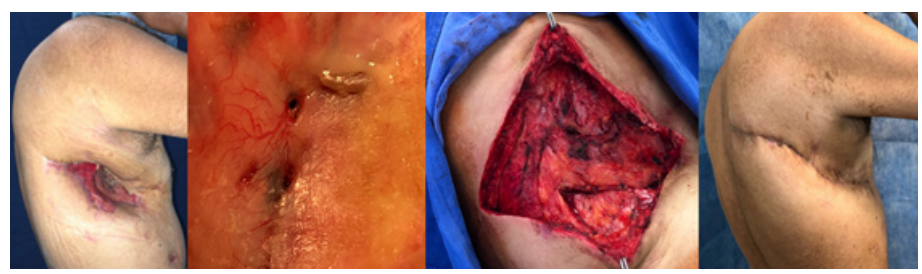

Case 3

A 67-year-old male, who had multiple rib fractures in the left hemithorax, was fixed with osteosynthesis material (titanium plates), in addition to empyema, which was treated with pleural lavage and decortication, submitted to negative pressure therapy for 76 days, he presented dehiscence of posterolateral surgical wound in left hemithorax, we proceeded to perform a muscular reconstruction with latissimus dorsi and anterior serratus, giving a closure of first intention. An adequate evolution was obtained, without complications, but with a poor aesthetic result and presenting partial skin dehiscences. In one year of follow-up, no pulmonary involvement was detected, with complete re-epithelization.

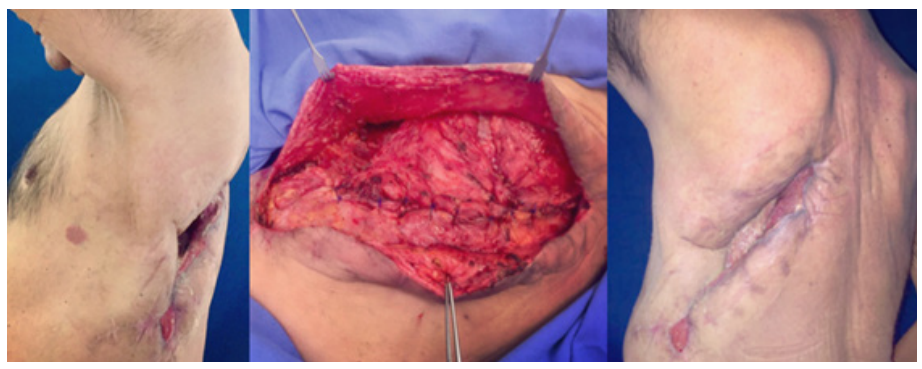

Case 4

A 54-year-old male with chronic pleural empyema, who was treated with a thoracic window, with a prolonged stay in the intensive care unit and assisted ventilatory support, presents a significant and deep continuity solution, a bloody area of $6 \times$ $6 \times 10 \mathrm{~cm}$, a reconstruction with latissimus dorsi was planned, with a satisfactory discharge without complications at one year of follow-up.

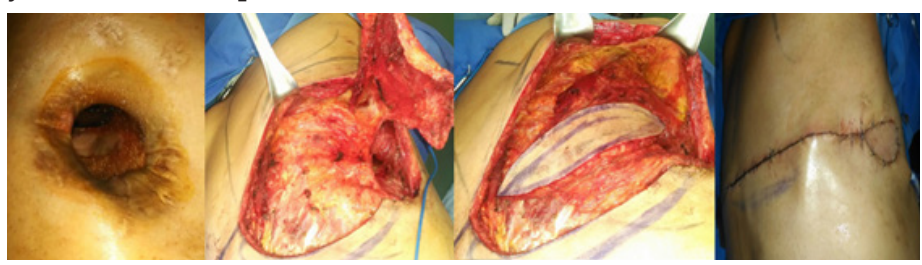




\section{Case 5}

A 29-year-old male with a neuroendocrine tumor in the right hemithorax, a tumor resection was performed by the oncology department, with immediate reconstruction with ipsilateral TRAM, with a satisfactory discharge 4 days later, with adequate integration of the flap without complications, patient dies 3 months after intervention, secondary to tumor recurrence.

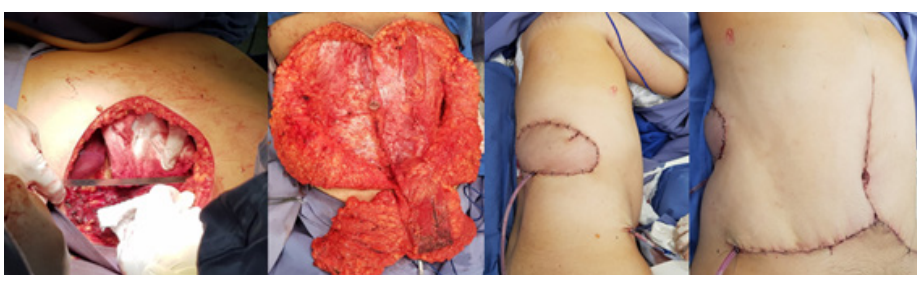

\section{DISCUSSION}

For the reconstruction of the thoracic wall it is of vital importance to have an appropriate knowledge of the thoracoabdominal anatomy, you must work jointly with the thoracic, cardiothoracic and oncologist surgeon, to individualize the surgical treatment in each patient [2] and yes It is an immediate reconstruction or in a second time. It is difficult to follow a reconstruction algorithm, so the attachment to the reconstructive scale is necessary. During surgical planning we must have different plans in case one fails, finally evaluate the aesthetic considerations, and the expectations of each patient. To carry out a complete thoracic reconstruction it is necessary to know the pulmonary physiology, to return the structural integrity of the thorax, [1] and to have a reliable and well-vascularized coverage of the soft tissues [3-17].

\section{CONCLUSIONS}

The reconstruction in patients with thoracic pathologies, are of great complexity, adequate coverage, stability to the thorax and an aesthetic result, as satisfactory as possible, should be provided, and the use of pedicled flaps provides a vascularized tissue, to return the integrity of the thorax.

\section{Conflicts of Interest}

The authors declare that they have no competing interests.

Funding: I did not received any funding of this article.

Ethical approval: Approval has been given by the ethics committee for the publication of this case.

Guarantor: Julio Palacios Juárez MD.

\section{REFERENCES}

1. Arnold PG and Pairolero PC. (1996). Chest-wall reconstruction: An account of 500 consecutive patients. Plast Reconstr Surg. 98(5): 804-810.

2. Losken A, Thourani VH, Carlson GW, Jones GE, et al. (2004). A reconstructive algorithm for plastic surgery following extensive chest wall resection. Br J Plast Surg. 57(4): 295302.

3. Thomas PA and Brouchet L. (2010). Prosthetic reconstruction of the chest wall. Thorac Surg Clin. 20(4): 551-558.

4. Pantelides NM, Young SS and Iyer S. (2017). The rectus abdominis muscle advancement flap as a salvage option for chest wall reconstruction. Ann R Coll Surg Engl. 99: e142-e144.

5. Mineo TC, Ambrogi V, Pompeo E, Cristino B, et al. (1997). Comparison between intercostal and diaphragmatic flap in the surgical treatment of early bronchopleural fistula. Eur J Cardiothorac Surg. 12(4): 675-677.

6. Brewer LA III, King EL, Lilly LJ and Bai AF. (1953). Bronchial closure in pulmonary resection: A clinical and experimental study using a pedicled pericardial fat graft reinforcement. J Thorac Surg. 26(5): 507-532.

7. Mineo TC and Ambrogi V. (1995). Early closure of the postpneumonectomy bronchopleural fistula by pedicled diaphragmatic flaps. Ann Thorac Surg. 60(3): 714-715.

8. Virkkula L and Eerola S. (1975). Use of omental pedicle for treatment of bronchial fistula after lower lobectomy: Report of two cases. Scand J Thorac Cardiovasc Surg. 9(3): 287-290.

9. Rathinam S, Venkateswaran R, Rajesh PB and Collins FJ. (2004). Reconstruction of the chest wall and the diaphragm using the inverted $Y$ Marlex methylmethacrylate sandwich flap. Eur J Cardiothorac Surg. 26(1): 197-201.

10. Le Roux BT and Shama DM. (1983). Resection of tumors of the chest wall. Curr Probl Surg. 20(6): 345-386.

11. Butler CE, Langstein HN and Kronowitz SJ. (2005). Pelvic, abdominal, and chest wall reconstruction with AlloDerm in patients at increased risk for mesh-related complications. Plast Reconstr Surg. 116(5): 1263-1275; discussion 1276. 
12. Deschamps C, Tirnaksiz BM, Darbandi R, Trastek VF, et al. (1999). Early and long-term results of prosthetic chest wall reconstruction. J Thorac Cardiovasc Surg. 117(3): 588-591; discussion 591-592.

13. Bauer JJ, Salky BA, Gelernt IM and Kreel I. (1987). Repair of large abdominal wall defects with expanded polytetrafluoroethylene (PTFE). Ann Surg. 206(6): 765-769.

14. Hyans P, Moore JH Jr and Sinha L. (1992). Reconstruction of the chest wall with e-PTFE following major resection. Ann Plast Surg. 29(4): 321-327.

15. Campbell KT, Burns NK, Rios CN and Mathur AB. (2011). Human versus non-cross-linked porcine acellular dermal matrix used for ventral hernia repair: comparison of in vivo fibrovascular remodeling and mechanical repair strength. Plast Reconstr Surg. 127(6): 2321-2332.

16. Ferraro P, Cugno S, Liberman M, Danino MA, et al. (2010). Principles of chest wall resection and reconstruction. Thorac Surg Clin. 20(4): 465-476.

17. Netscher DT, Baumholtz MA and Bullocks J. (2009). Chest reconstruction: II. Regional reconstruction of chest wall wounds that do not affect respiratory function (axilla, posterolateral chest, and posterior trunk). Plast Reconstr Surg. 124(6): 427e-435e. 